\title{
SIMULASI GERAK TRANSLASI DAN GERAK MELINGKAR MENGGUNAKAN VBA MACRO EXCEL MELALUI PROJECT BASED LEARNING (PBL)
}

\author{
Ahmad Swandi ${ }^{1 *}$, Sri Rahmadhanningsih², Muthmainah'², Risky Afandi Putri², Sparisoma Viridi \\ Nurhayati $^{4}$, Ahmad Suryadi ${ }^{5}$ \\ (1) Pendidikan Fisika, Fakultas Keguruan dan Ilmu Pendidikan, Universitas Bosowa \\ (2) Program Pascasarjana, Institut Teknologi Bandung \\ (3) Prodi Sains Komputasi, Departemen Fisika, Fakultas Matematika and Ilmu Pengetahuan Alam, Institut Teknologi \\ Bandung \\ (4) Prodi PGSD, STKIP Singkawang \\ (5) Pendidikan Fisika, Universitas Negeri Malang \\ *Corresponding Author : ahmad.swandi@universitasbosowa.ac.id
}

\begin{abstract}
Abstrak
Interactive simulations have been widely used in physics learning at all levels of education. However, most of the simulations used are downloaded from the internet. The importance of physics teacher / teacher skills in making interactive physics simulations is an obligation. Various software that can be used to create physics simulations, one of which is the Macro Visual Basic for Application Excel (VBA). This study aims to create an interactive physics simulation on the concept of translational motion and circular motion using VBA Excel with product development steps using PBL Gold Standard divided into 7 steps, namely Challenging Problems or Questions, Sustained Inquiry, Authenticity, Student Voice and Choice, Reflection, Criticism. and Revisions and Public Products. After the work process of translational motion simulation projects and dynamic motion, which can then be used in physics learning..
\end{abstract}

Keywords: Visual Basic for Application (VBA), PBL Gold Standard

\section{Pendahuluan}

Penggunaan simulasi fisika yang interaktif terbukti sangat bermanfaat digunakan dalam pembelajaran sebab mampu memvisualisasikan gambaran-gambaran fenomena fisika didalam kelas. Beberapa penelitian telah banyak dilakukan untuk melihat bagaimana media simulasi dikembangkan, cara penggunaannya didalam pembelajaran fisika dan efektifitas dari hasil penggunaan simulasi. Seperti yang dilakukan oleh Swandi dkk yang mengembangkan teknologi simulasi yang mampu mengarahkan mahasiswa lebih aktif dalam pembelajaran sehingga pemahaman konsep dan keaktifan peserta didik meningkat (Ahmad \& Bunga, 2015; A. Swandi, Amin, Viridi, \& Eljabbar, 2020). Media simulasi yang dikembangkan menggunakan aplikasi berbagai jenis aplikasi seperti Lectora, camtasia dan i-spring dengan mengadopsi simulasi dari internet (Nurdianto, Safiuddin, \& Eso, 2020; Ahmad Swandi, Nurul, \& Irsan, 2015). Raja Mahmud dkk menerapkan simulasi komputer melalui model pembelajaran Problem Based Learning dan berhasil meningkatkan keterampilan pemecahan masalah mahasiswa pada materi impuls dan momentum (Nuroso \& Arifin, 2012). Selain itu, beberapa peneliti juga menggunakan simulasi yang diambil dari internet seperti penggunaan simulasi $\mathrm{PhET}$ dalam pembelajaran fisika untuk meningkatkan hasil belajar pada materi listrik dinamis (Sinulingga, Hartanto, \& Santoso, 2016). Penelitian yang dilakukan Syarifah Fithriani bertujuan untuk mengetahui penggunaan media simulasi PhET dengan pendekatan inkuiri terbimbing untuk meningkatkan keterampilan berpikir kritis pada pokok bahasan kalor (Palloan \& Swandi, 2019). Simulasi PhET ini cukup menarik karna disajikan bukan hanya dalam bahasa Inggirs tetapi juga bahasa Indonesia. Selain itu, simulasi dapat dengan mudah di download dan digunakan. Beberapa animasi yang berkaitan dengan fisika juga dapat kita temukan di internet. Namun, simulasi-simulasi fisika yang interaktif kita temukan di internet tidak mencakup semua konsep fisika. Selain itu penggunaan bahasa inggris pada simulasi tersebut menjadi permasalahan bagi guru dan mahasiswa. 
Sangat penting bagi guru untuk mengembangkan simulasi sesuai dengan konsep dan kebutuhan mereka. Salah satu software yang dapat digunakan dalam membuat simulasi fisika menggunakan VBA Excel dikenal luas oleh guru atau pengajar, selain itu software ini gratis dan mudah digunakan. Beberapa penelitian sebelumnya telah berhasil mengembangan simulasi dengan VBA Excell seperti penelitian yang dilakukan oleh Erwin yang berhasil mengembangan simulasi tentang gerak benda yang dijatuhkan dan dilepaskan secara horizontal (A. Swandi, F. Muin, \& B. D. Amin, 2018). Ewis Amalya mengembangan visualisasi gelombang menggunakan VBA Excel dan produk yang dihasilkan dinyatakan valid dan reliabel namun belum diterapkan dalam pembelajaran fisika (Amalya, M. Rahmad, \& Syahril, 2018). Selain itu Hari Wibowo merancang simulasi komputer untuk pembelajaran fisika pada topik selektor kecepatan dengan Metode Numerik Euler pada VBA Excel dan produk yang dihasilkan juga berada pada ketegori valid (Wibowo, 2018). Pada pembelajaran vokasi (SMK), visual basic for application spreadsheet excel dapat juga diaplikasikan untuk membuat simulasi konsep motor listrik tiga fasa dan aplikasinya sebagai media pembelajaran (Harjono, Sahidu, \& Herayanti, 2017). Nurdianto dkk juga membuat simulasi ersamaan Difraksi Fraunhofer pada celah lingkaran dengan menggunakan Visual Basic for Application (VBA) Spreadsheets Excel (Tesi Muskania \& Wilujeng, 2017).

Namun, bagaimana simulasi dengan VBA Excel dibuat ?Apa langkah-langkah yang dapat dilakukan agar produk dapat dikembangkan dengan baik? Bagaimana bentuk bahasa pemprograman yang digunakan? Seperti apa pengujiannya? Hampir semua simulasi fisika yang dibuat tidak menyertakan cara pembuatannya dengan jelas serta bahasa pemprograman yang lengkap. Sehingga guru tidak memiliki referensi dalam membuat sendiri simulasi fisika denga VBA Excel. Oleh karena itu peneliti melakukan proyek untuk membuat simulasi dan menyajikan secara lengkap langkah-langkah dan bahasa pemprograman yang digunakan. Sebagai mahasiswa pascasarjana, salah satu metode yang dapat dilakukan dalam menghasilkan produk simulasi adalah dengan mengikuti tahapan Project
Based Learning (PjBL). Pada umumnya dosen atau guru menggunakan $\mathrm{PjBL}$ untuk sistem pembelajarannya sehingga pembelajaran menghasilkan kualitas yang baik dan mencari keterkaitan antara pelaksanaan $\mathrm{PjBL}$ dengan berbagai variabel. Misalnya, penelitian yang dilakukan oleh Al-Tabany menggunakan PjBl untuk mengetahui pengaruhnya terhadap pemahaman konseptual dan pengembangan keterampilan seperti kolaborasi, berpikir kritis dan pemecahan masalah. Begitu pula dengan penelitian yang dilakukan oleh Trianto yang menyatakan bahwa terjadi peningkatan motivasi belajar dan hasil belajar mahasiswa meningkat setelah pembelajaran menggunakan model $\mathrm{PjBL}$ (Gunawan, Harjono, \& Sahidu, 2015). Selain itu, Rashid dan Bakar menyatakan bahwa PjBL dapat melatih mahasiswa untuk membina kemampuan komunikasi dan tim kerja. Namun dari semua penelitian tersebut, PjBL hanya digunakan untuk memperbaiki atau mempelajari pengaruhnya terhadap variabel tertentu. Padahal PjBL harus bisa dimanfaatkan oleh dosen untuk menghasilkan produk yang bisa dikerjakan oleh mahamahasiswa dan memiliki manfaat yang luas (Tesi Muskania \& Wilujeng, 2017).

Berdasarkan penjelasan di atas mengenai penggunaan PjBL Gold Standard dalam pembelajaran fisika di perguruan tinggi. Maka peneliti membuat simulasi fisika yang interaktif pada konsep gerak translasi dan gerak melingkar dengan menerapkan metode PjBL ketika masih berstatus mahasiswa pascasarjana Institut Teknologi Bandung. Pembelajaran fisika di perguruan tinggi hendaknya bukan hanya fokus pada pembelajaran teori dalam kelas tetapi bagaimana dosen mengeksplorasi kemampuan mahasiswa dalam mendesain sebuah aktivitas untuk menghasilkan produk yang bermanfaat berdasarkan pemahaman teori yang telah mereka dapatkan didalam kelas. Hal inilah yang dilakukan oleh para dosen fisika di Institut Teknologi Bandung. Setelah dilakukan pembelajaran tatap muka dikelas selama 8 minggu, dosen kemudian mengkombinasi sistem pembelajaran menjadi 2 yaitu pembelajaran teori dalam kelas dan pembelajaran berbasis proyek yang dilakukan secara individu atau tim. Pada mata kuliah fisika komputasi, berbagai proyek dapat dilakukan untuk menghasilkan produk yang 
bermanfaat khsusunya dalam pembelajaran fisika. Salah satunya adalah pengembangan simulasi fisika yang interaktif menggunakan VBA excel.

Melalui artikel ini, peneliti mencoba menjelaskan bagaimana langkah-langkah pengerjaaan sebuah proyek mahamahasiswa di perguruan tinggi sehingga bisa diadaptasi oleh institusi yang lain. Selain itu, artikel diharapkan dapat menjadi pedoman bagi guru, mahamahasiswa atau peneliti dalam membuat simulasi dengan VBA excel dengan menyajikan bahasa pemprograman yang dapat diikuti oleh guru, mahamahasiswa atau peneliti untuk pengembangan lebih lanjut.

\section{Metode}

Penelitian ini termasuk laboratorium eksperimental yang merupakan bagian dari pengerjaan proyek pada mata kuliah fisika komputasi. Penelitian dilakukan di laboratorium komputasi fisika dengan membuat simulasi interaktif pada konsep gerak translasi dan gerak melingkar menggunakan metode Gold Standard Project Based Learning melalui 7 langkah yaitu (1) Tantangan Permasalahan atau Pertanyaan, (2) Kajian yang Berkelanjutan, (3) Pengujian Keaslian, (4) Peran Mahasiswa, (5) Refleksi, (6) Kritik dan Revisi, (7) Publikasi Produk (Candra, Flaminggo, Natalia, Yuliza, \& Khairurrijal, 2019). Penelitian ini bertujuan untuk menghasilkan visualisasi dan nilai-nilai dari parameter fisis berkaitan dengan Gerak Lurus Beraturan (GLB), Gerak Lurus Berubah Beraturan (GLBB) dan Gerak Melingkar Beraturan (GMB). Aplikasi yang digunakan adalah Visual Basic for Application Excel.. Selain memvisualisasikan gerak sebuah benda, aplikasi ini juga dapat menampilkan nilai parameterparameter fisis pada waktu tertentu.

\section{Hasil dan Pembahasan}

\subsection{Tantangan Permasalahan atau Pertanyaan}

Pada awal pengerjaan proyek, tim atau mahamahasiswa ditantang oleh dosen mata kuliah fisika komputasi untuk memanfaatkan ilmu dan keterampilan yang telah diperoleh dalam mata kuliah komputasi untuk membuat sebuah proyek yang memiliki luaran dan bisa digunakan oleh orang lain. Tim kemudian melakukan pendalaman referensi dan diskusi sehingga ditemukan suatu masalah yaitu adanya kesulitan guru dalam membuat media simulasi fisika yang interaktif, sesuai dengan kurikulum yang ada serta menggunakan aplikasi yang telah dikenal luas oleh para guru. Selanjutnya, beberapa pertanyaan dirumuskan seperti, materi apa yang akan dibuatkan simulasinya?, mengapa materi itu dipilih?. Tim kemudian berdiskusi dengan dosen tentang topik permasalahan yang didapat. Akhirnya tim dan dosen sepakat untuk membuat simulasi terkait topik gerak translasi dan gerak melingkar. Berdasarkan hasil penulusuran tim, tidak peroleh media simulasi pada konsep tersebut yang menggunakan aplikasi yang sama. Aplikasi yang digunakan dalam penelitian ini adalah Visual Basic for Application Excel. Hal ini dikarenakan aplikasi ini telah dikenal luas dan dimiliki oleh guru di komputer masing-masing.

\subsection{Kajian yang Berkelanjutan}

Sebelum memulai proses kerja proyek dalam membuat simulasi. Pertanyaan lebih lanjut muncul. Pertanyaan pertama adalah apa yang membedakan proyek ini dengan proyek lainnya?. Meskipun telah banyak dilakukan penelitian lainnya tentang penggunaan VBA excel dalam membuat simulasi, namun belum ada peneliti yang melampirkan bahasa pemprograman yang mereka gunakan secara detail, sehingga sulit bagi guru untuk membuat dan mengembangkan simulasi lainnya. Selain itu, simulasi yang dikembangkan sebaiknya bersifat interaktif, artinya pengguna dapat memasukkan data besaran fisika dan ketika dilakukan running, fenomena fisika akan dapat diamati dilayar komputer dan nilai besaran fisika lainnya dapat diketahui. Selanjutnya bagaimana media simulasi dibuat? Media simulasi yang dikembangkan dibagi menjadi 3 yaitu gerak lurus beraturan, gerak lurus berubah beraturan dan gerak melingkar. Selain itu pada masing-masing konsep tersebut ada 3 bagian yang dikembangkan yaitu userform yang berfungsi sebagai menu untuk memasukkan besaran fisika, yang kedua adalah simulasi yang memvisualisasikan fenomena fisika dan selanjutnya adalah tabel yang mampu menunjukkan nilai besaran fisika lainnya ketika program sedang running. Berikut adalah tampilan userform untuk konsep gerak lurus berubah beraturan. 


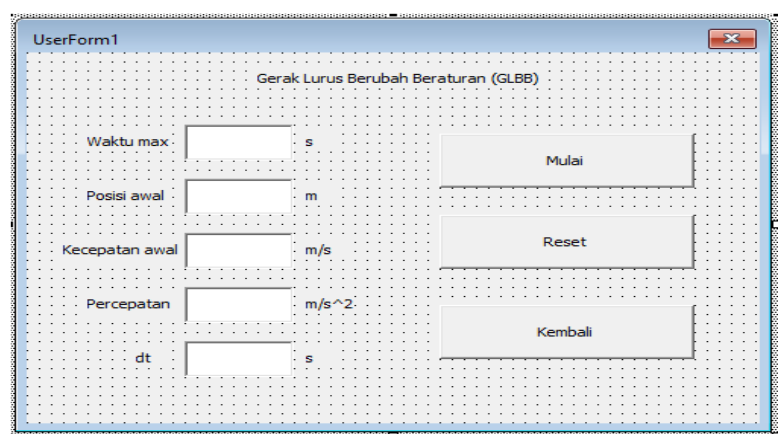

Gambar 1. Userform pada simulasi GLBB

Pada userform ini, pengguna dapat memasukkan waktu maksimum program melakukan running, posisi awal benda, kecepatan awal, dan percepatan. Ketika pengguna mengklik tombol "mulai" maka partikel akan bergerak lurus berubah beraturan hingga waktu maksimum tercapai. Jika pengguna ingin memasukkan nilai besaran lainnya maka dapat mengklik tombol reset. Berikut adalah source code untuk membuat userform.

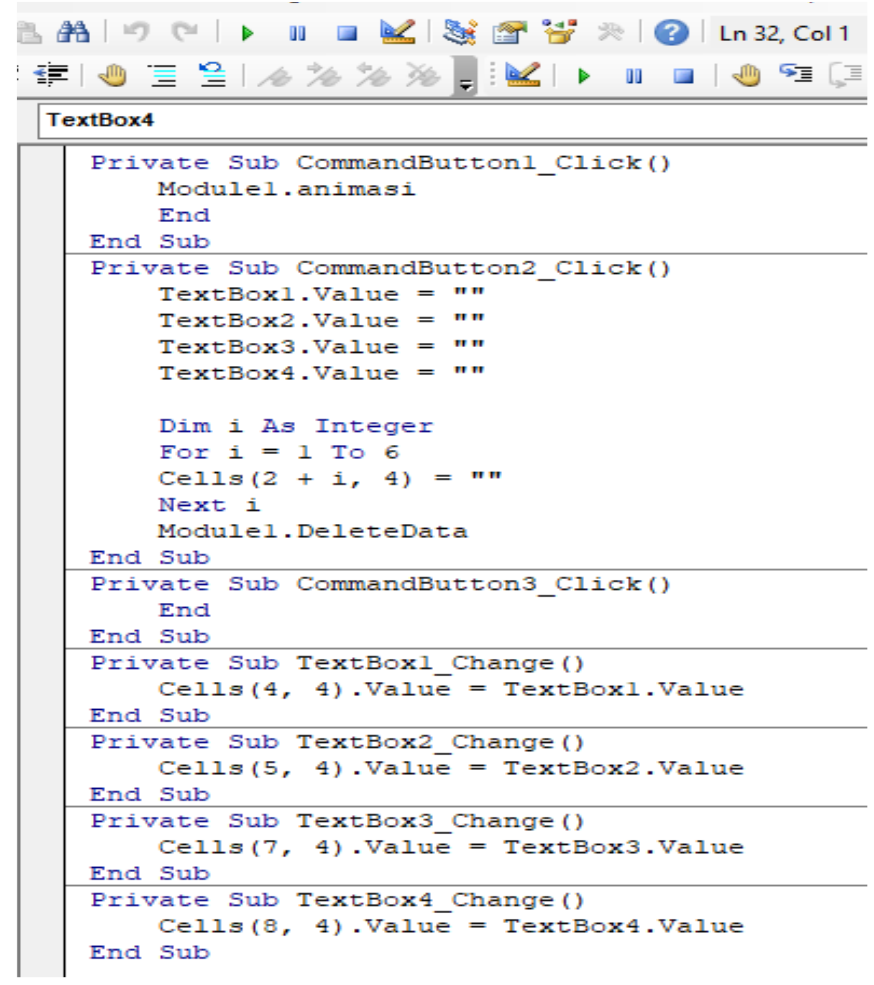

Gambar 2. Source Code untuk membuat Userform dan menghubungkan dengan module (simulasi GLBB)

Selanjutnya adalah bagaimana membuat simulasi pada masing-masing konsep tersebut. Simulasi dapat berjalan dengan memasukkan bahasa pemprograman dibagian module VBA excel yang telah terhubung dengan userform. Adapun bahasa pemprograman gang digunakan untuk konsep GLBB adalah seperti pada lampiran 1.
Setelah Source Code dibuat maka dilakukan desain tampilan simulasi yang diinginkan. Persamaan yang diinput dalam module pada masing-masing konsep menggunakan persamaan masing-masing yang diperoleh dari referensi.

\subsection{Keasilian}

Simulasi yang telah dikembangkan harus dapat beroperasi ketika pengguna memberi perlakuan. Dalam hal ini, ketika pengguna memasukkan nilai besaran-besaran fisika maka benda dapat bergerak sesuai dengan teori yang ada. Pengembangan program dibuat agar mudah digunakan. Dalam simulasi ini, program dibagi menjadi tiga yatu input (userform), output yang menampilkan nilai besaran fisika dan selanjutnya bagian simulasi. Untuk mengetahui apakah simulasi dapat berjalan dengan baik dan nilai besaran lainnya sesuai dengan teori maka dilakukan pengujian, pengguna dapat memasukkan nilai besaran fisika dibagian userform dan kemudian mengklik "mulai" sehingga benda akan bergerak sesuai dengan konsep yang ada seperti pada lampiran 2. Selain itu akan ditampilkan nilai besaran fisika lainnya pada saat waktu tertentu.

\subsection{Peran Mahasiswa}

Saat melaksanakan proyek ini, kelompok kami sebagai pelaku proyek membuat keputusan berdasarkan pengetahuan dan informasi kami dari literatur maupun pengalaman tim ketika menjadi guru fisika. Beberapa keputusan yang kami ambil misalnya, (i) tema topik dari proyek yang akan dilakukan, masalah dan solusi yang diberikan; (ii) kualitas simulasi yang kami kembangkan, penentuan besaran fisika pada userform yang digunakan pada masing-masing simulasi; (iii) untuk menguji apakah simulasi berjalan dengan baik sesuai teori yang ada, kami menampilkan data yang interaktif yang berubah-ubah mengikuti posisi partikel/benda yang sedang bergerak. Ide dan keputusan yang dikembangkan oleh tim kami di atas membuat peserta proyek merasa lebih terlibat dalam proses tersebut. Setiap ide disampaikan terlebih dahulu kepada dosen selama proses pembelajaran.

\subsection{Refleksi}

Dalam pengerjaan proyek melalui PBL Standard Gold yang dikembangkan oleh Buck Institute of 
Technology (Candra et al., 2019; A. Swandi, A. Aprianto \& S. Rahmadhanningsih, 2020), kami memperoleh pengalaman belajar yang banyak baik sebagai tim maupun secara individu, (i) pembelajaran dengan PBL membuat lebih menyenangkan, berkesan dan menarik serta terdapat interaksi yang mendalam dalam bentuk pertanyaan dan jawaban antara dosen dan tim. Konsep, metode, produk yang kami dapatkan diuji secara menyeluruh. Hal ini sesuai dengan pendapat Canra dkk yang menyatakan dengan adanya PBL dosen dan tutor atau menantang tim untuk melakukan aktivitas fisik yang menantang di laboratorium sehingga proses pembelajaran terasa lebih bermakna dari sekedar pembelajaran teoritis (Candra et al., 2019). (ii) PBL dengan Gold Standard yang kita ikuti dapat meningkatkan keterampilan pemecahan masalah. Tim belajar untuk mengumpulkan data dan menemukan solusi yang paling efektif dan efisien untuk suatu masalah. Hal itu sejalan dengan pendapat Thomas yang menyatakan bahwa dengan PBL mampu mengajarkan kepada mahasiswa tentang proses penyelesaian berbagai masalah dari informasi awal. Informasi awal diperoleh dari mahasiswa yang dilanjutkan dengan pemberian soal ke jenjang yang lebih tinggi sehingga melatih mahasiswa untuk menganalisis jawaban atas pertanyaan tersebut dan melatih mahasiswa untuk memecahkan masalah. Astawa mengutip fokus pembelajaran proyek pada proses investigasi mendalam yang melibatkan proses tanya jawab yang panjang dan ketat, menggunakan sumber daya dan mengembangkan jawaban; dan fokus pada pertanyaan terbuka untuk memahami dan menangkap perhatian mahasiswa dalam menangkap proyek ( A. Swandi, A. Aprianto \& S. Rahmadhanningsih, 2020).

Muskania \& Wilujeng menyampaikan bahwa PBL diawali dengan pemberian masalah oleh dosen yang mengarah pada produk akhir yang akan dihasilkan mahamahasisw (Tesi Muskania \& Wilujeng, 2017). (iii) Tim proyek juga dilatih untuk meningkatkan keterampilan berpikir kritis. Masalah dan pertanyaan awal diperoleh dan dikonsultasikan oleh para ahli, sehingga menimbulkan banyak pertanyaan baru dan cukup kompleks. Tim diminta untuk bisa berpikir kritis tentang pertanyaan tersebut. Hal ini sejalan dengan pendapat Hendrik \& Ihtiari yang menjelaskan bahwa proses pembelajaran berbasis proyek dalam suatu aplikasi mendukung pengembangan dan peningkatan kemampuan berpikir kritis mahasiswa (Pratama \& Prastyaningrum, 2016). Lebih lanjut Sumarni menyatakan bahwa melalui proyek, mahasiswa tidak perlu menghafal suatu teori atau persamaan (rumus), melainkan menganalisis dan berpikir kritis dengan menganalisis informasi secara kolaboratif untuk menyelesaikan masalah melalui proyek (Sumarni, 2015). Pendekatan pragmatis ini lebih berkonsentrasi pada proses daripada konten.

Selain itu, Berkolaborasi dengan tim selama pembelajaran proyek merupakan kegiatan yang sangat penting. Kolaborasi adalah salah satu ciri mengerjakan proyek dengan tujuan membantu mahasiswa bertukar ide dan berkomunikasi. Astawa, Artini, \& Nitiasih menjelaskan tahap pembelajaran proyek melatih mahasiswa untuk aktif dan berpikir kreatif serta terlibat dalam berkolaborasi dalam proyek (Astawa, Artini, \& Nitiasih, 2017). Pembelajaran berbasis proyek memungkinkan mahasiswa untuk mendapatkan pemahaman yang lebih dalam tentang materi dengan berkolaborasi dan menggunakan ide-ide mereka (konstruksi aktif). Interaksi sosial memungkinkan mahasiswa untuk bekerja dengan orang lain untuk membangun pengetahuan bersama. Williams menjelaskan bahwa pembelajaran berbasis proyek memberikan kesempatan kepada mahasiswa untuk terlibat aktif selama pembelajaran dan kesempatan untuk mempelajari soft skill baru seperti keterampilan seperti kolaborasi, komunikasi, dan negosiasi (Williams, 2017). Selain itu, Lihat et al. Dinyatakan bahwa keterampilan komunikasi dan kerjasama tim merupakan keterampilan yang dapat dilatihkan melalui kegiatan proyek (See, Rashid, \& Bakar, 2015). Harper melanjutkan, PBL merupakan salah satu elemen penting yang dapat melatih keterampilan abad 21, salah satunya adalah keterampilan komunikasi A. Swandi, A. Aprianto \& S. Rahmadhanningsih, 2020). Tahap terakhir dari pembelajaran berbasis proyek adalah mengevaluasi kegiatan proyek yang telah dilaksanakan. Berdasarkan pengalaman, tim merasa senang dan termotivasi dalam membuat proyek yang telah mereka selesaikan. Mahasiswa memperoleh lebih banyak pengetahuan dan keterampilan baru selama penyelesaian proyek 
sambil merasa tertantang untuk menyelesaikan proyek tersebut. Hal tersebut dikemukakan oleh Sumarni bahwa salah satu keuntungan menggunakan PBL dalam pembelajaran dapat meningkatkan motivasi belajar mahasiswa (Agustina, Astuti, Sumarni, \& Saraswati, 2017).

Selain poin-poin di atas, metode $\mathrm{PBL}$ juga berhasil melatih mahasiswa dalam beberapa soft skill, diantaranya kemampuan memutuskan dan mempertimbangkan sesuatu untuk mengevaluasi kemajuan pekerjaan dan mengembangkan berpikir kritis. Selain itu, PBL juga memberikan pengalaman berharga tentang bagaimana dibimbing oleh para ahli untuk menemukan masalah dan menyelesaikannya dengan langkahlangkah ilmiah. Dengan berbagai refleksi yang disebutkan di atas, tim kami berharap kemampuan ini dapat bermanfaat untuk pengembangan individu masing-masing peserta proyek, serta untuk lebih mengembangkan produk yang kami rancang di masa mendatang.

\subsection{Kritik dan Revisi}

Selama pengerjaan proyek, tim kami menerima banyak kritik dan saran dari para dosen, pakar dan tutor. Kritik dan saran ini untuk kepentingan proyek kami saat ini, serta pengembangan masa depan. Beberapa kritik yang dilontarkan oleh dosen dan tutor adalah: (i) agar lebih lebih menarik, bentuk benda diubah menjadi bentuk yang lebih nyata, seperti diganti dengan gambar mobil atau benda lain yang dapat bergerak; (ii) simulasi tidak hanya menunjukkan posisi benda tetapi juga mampu menunjukkan kecepatan benda pada waktu tertentu untuk simulasi GLBB; (iii) Selain itu para ahli menyarankan agar jejak benda ditampilkan sehingga gerakan benda lebih terlihat nyata khususnya pada simulasi GMB. Namun karena keterbatasan waktu dalam penggunaan laboratorium konputasi, maka kritik dan saran tersebut belum dilakukan perbaikin. Hal ini dapat menjadi pekerjaan lanjutan bagi guru atau mahasiswa yang ingin mengembangkan simulasi ini dengan menggunakan aplikasi yang sama.

\subsection{Publikasi Produk}

Produk yang dihasilkan dalam Pembelajaran Berbasis Proyek ini disebut "Simulasi Gerak Ttranslasi dan Gerak Melingkar', Proses selanjutnya yang harus diikuti untuk menerapkan
PBL Gold Standard adalah penyajian produk yang telah dihasilkan. Tim kami menyiapkan slide dan memastikan kesiapan produk yang dikembangkan untuk pengenalan dosen, pakar, tutor, dan sesama mahasiswa. Produk akhir dari proyek ini dapat dimanfaatkan oleh masyarakat khususnya dalam pembelajaran fisika untuk konsep medan listrik baik di sekolah maupun perguruan tinggi.

\section{Kesimpulan}

Dari hasil penelitian, pengolahan data, hasil dan pembahasan dapat diambil kesimpulan sebagai berikut: Telah dihasilkan simulasi Gerak Translasi dan Gerak Melingkar dengan menggunakan fitur pada Microsoft Excel dan Macro VBA melalui tahapan PBL Gold Standard. Produk dari penelitian ini dapat menjadi referensi bagi para guru dan peserta didik untuk menggunakan media simulasi pada gerak translasi dan gerak rotasi sehingga pembelajaran fisika lebih menarik dan interaktif. Selain itu dengan adanya langkahlangkah pengembangan simulasi yang disertai dengan bahasa pemprograman yang sangat rinci, dapat menjadi acuan bagi para guru atau peneliti lainnya untuk membuat media simulasi fisika yang lebih menarik. Untuk itu, penelitian selanjutnya perlu mengembangkan penelitian ini dalam tiga bentuk dimensi (3D) agar tampilannya lebih menarik. Peneliti dapat menggunakan metode penelitian pengembangan dan penerapan produk dilapangan.

\section{Daftar Pustaka}

Agustina, I., Astuti, D., Sumarni, R. A., \& Saraswati, D. L. (2017). Pengembangan Media Pembelajaran Fisika Mobile Learning berbasis Android. Journal Penelitian dan Pengembangan Pendidikan Fisika. 3(1), 5762.

Ahmad, S., \& Bunga, D. A. (2015). Pengembangan Media Simulasi Interaktif Berbasis Web untuk Meningkatkan Aktivitas Belajar Peserta Didik. Prosiding Pertemuan Ilmiah XXIXHFI Jateng \& DIY, (April), 192-195. Retrieved from https://studylibid.com/doc/907975/fullpengembangan-media-simulasi-interaktif--hfi-diy

Amalya, E., M. Rahmad, M. R., \& Syahril, S. 
(2018). Perancangan Visualisasi Gelombang Berbasis VBA Dengan Microsoft Excel Sebagai Media Pembelajaran Fisika Siswa Sma. Jurnal Geliga Sains: Jurnal Pendidikan Fisika, 5(2), 95.

https://doi.org/10.31258/jgs.5.2.95-103

Astawa, N. L., Artini, L. P., \& Nitiasih, P. K. (2017). Project-based Learning Activities and EFL Students' Productive Skills in English. Journal of Language Teaching and Research, 8(6), 1147. https://doi.org/10.17507/jltr.0806.16

Candra, R., Flaminggo, N., Natalia, A., Yuliza, E., \& Khairurrijal, K. (2019). Making Counter Clockwise Analog Thermometer under Project-based Learning Method. Journal of Physics: Conference Series, 1204(1). $\quad$ https://doi.org/10.1088/17426596/1204/1/012116

Gunawan, Harjono, A., \& Sahidu, H. (2015). Pengembangan Model Laboratorium Virtual Berorientasi Pada Kemampuan Pemecahan Masalah Bagi Calon Guru Fisika. Prosiding Seminar Nasional Fisika Dan Pendidikan Fisika (SNFPF), 6(1), 232-237. Retrieved from jurnal.fkip.uns.ac.id/index.php/fisika/article/ view/7782\%0A

Harjono, A., Sahidu, H., \& Herayanti, L. (2017). Virtual Laboratory Of Electricity Concept To Improve Prospective Physics Teachers ' Creativity. JurnalnPendidikan Fisika Iindonesia, 13(2), 102-111. https://doi.org/10.15294/jpfi.v13i2.10152

Swandi, A., Amin, B.D., \& Muin, F. (2018). 21th century physics learning in senior high school through interactive computer simulation to enhance students achievement. International Conference on Mathematics and Science Education of Universitas Pendidikan Indonesia. 3(1), 130-135.

Nurdianto, N., Safiuddin, L. O., \& Eso, R. (2020). Simulasi Persamaan Difraksi Fraunhofer pada Celah Lingkaran dengan Menggunakan Visual Basic for Application (VBA) Spreadsheets Excel. Jurnal Penelitian Pendidikan Fisika, 5(3), 215. https://doi.org/10.36709/jipfi.v5i3.13812

Nuroso, H., \& Arifin, A. (2012). Pemanfaatan Microsoft Excel Untuk Media Pembelajaran Fisika Pokok Bahasan Gerak Dengan Bantuan Camtasia Studio 4. Jurnal Penelitian Pembelajaran Fisika, 2(1/April), 78-88.

https://doi.org/10.26877/jp2f.v2i1/april.128

Palloan, P., \& Swandi, A. (2019). Development of learning instrument of active learning strategy integrated with computer simulation in physics teaching and learning on makassar state university. Journal of Physics: Conference Series, 1157(3).

https://doi.org/10.1088/1742-

$6596 / 1157 / 3 / 032016$

Pratama, H., \& Prastyaningrum, I. (2016). Pengaruh Model Pembelajaran Project Based Learning Berbantuan Media Pembelajaran Pembangkit Listrik T. Jurnal Penelitian Fisika Dan Aplikasinya (JPFA), 6(2), 44-50.

See, Y. G., Rashid, A. M., \& Bakar, A. R. (2015). The Effect of Project Based Learning on Level of Content Knowledge of PreVocational Subject. Mediterranean Journal of Social Sciences, 6(6), 369-375. https://doi.org/10.5901/mjss.2015.v6n6s4p36 9

Sinulingga, P., Hartanto, T. J., \& Santoso, B. (2016). Implementasi Pembelajaran Fisika Berbantuan Media Simulasi PhET untuk Meningkatkan Hasil Belajar Siswa Pada Materi Listrik Dinamis. Jurnal Penelitian \& Pengembangan Pendidikan Fisika, 2(1), 5764. https://doi.org/10.21009/1.02109

Sumarni, W. (2015). The Strenghths and Weaknesess of the Implementation of Project Based Learning: A Review. International Journal of Science and Research (IJSR), 4(3), 478-484. Retrieved from https://www.ijsr.net/archive/v4i3/SUB15202 3.pdf

Swandi, A., Amin, B. D., Viridi, S., \& Eljabbar, F. D. (2020). Harnessing technology-enabled active learning simulations (TEALSim) on modern physics concept. Journal of Physics: Conference Series, 1521(2). 
https://doi.org/10.1088/1742-6596/1521/2/022004

Swandi, A., Afrianto, A \& Rahmadhanningsih, S, M. (2020). Project Based Learning Based on Laboratory Experiments to Produce Laser Diffraction Experimental Devices on CD and DVD with 2 Measurement Methods. Indonesian Journal of EducationaL Studies. 23(2), 108-117.

Swandi, Ahmad, Nurul, S. H., \& Irsan. (2015). Pengembangan Media Pembelajaran Laboratorium Virtual untuk Mengatasi Miskonsepsi Pada Materi Fisika Inti di SMAN 1 Binamu, Jeneponto. Jurnal Fisika Indonesia. 18(52), 20-24.

https://doi.org/10.22146/jfi.24399

Tesi Muskania, R., \& Wilujeng, I. (2017). Pengembangan Perangkat Pembelajaran Project-Based Learning Untuk Membekali Foundational Knowledge Dan Meningkatkan scientific literacy. Jurnal Cakrawala Pendidikan, 36(1), 34-43.

https://doi.org/10.21831/cp.v36i1.8830

Wibowo, H. A. C. (2018). Rancang Bangun Simulasi Komputer untuk Pembelajaran Fisika pada Topik Selektor Kecepatan dengan Metode Numerik Euler. JIPVA (Jurnal Pendidikan IPA Veteran), 2(2), 141. https://doi.org/10.31331/jipva.v2i2.684

Williams, S. (2017). Investigating the allocation and corroboration of individual grades for project-based learning. Studies in Educational Evaluation, 53(June 2017), 1-9. https://doi.org/10.1016/j.stueduc.2016.10.00 9 


\section{Lampiran 1.}

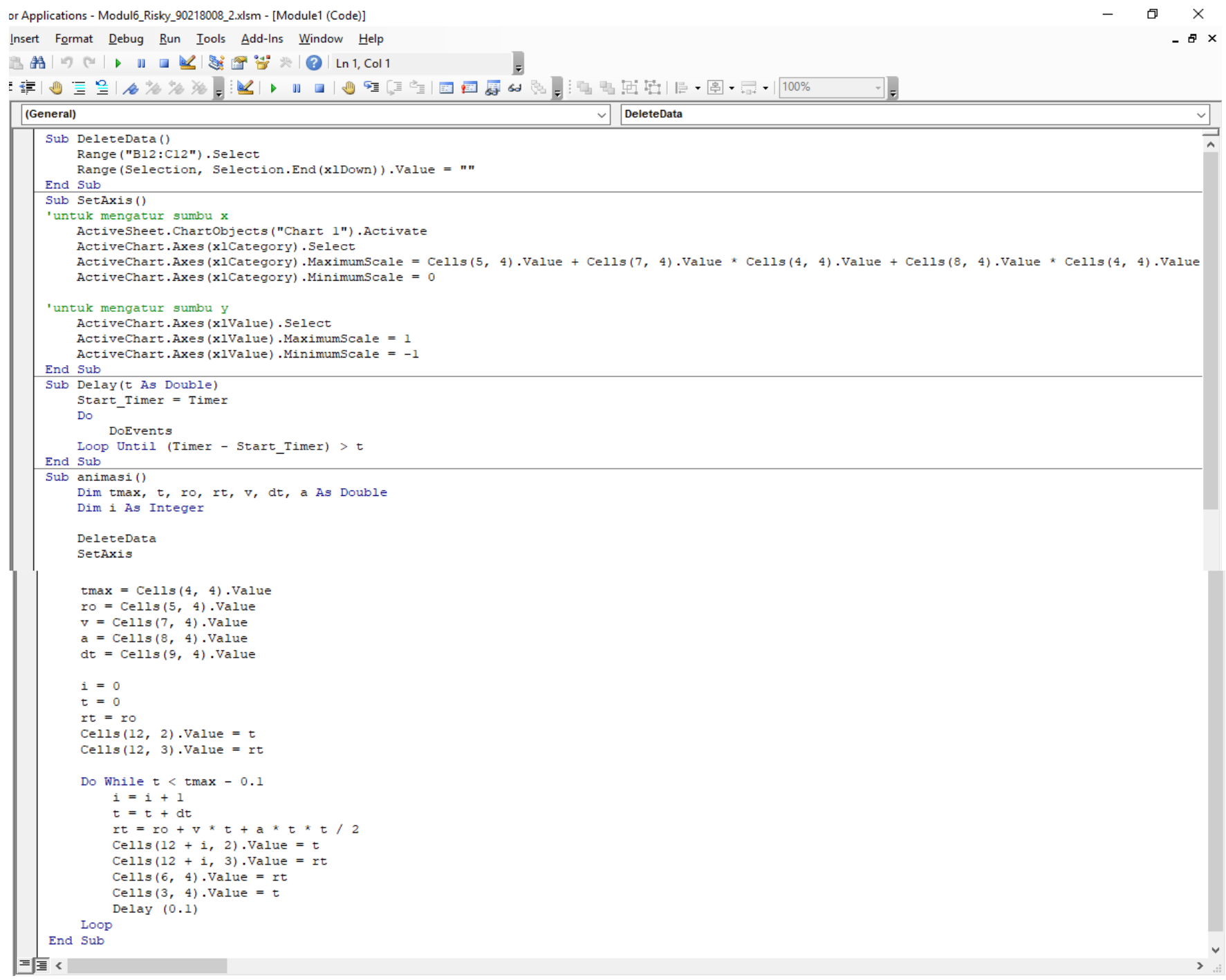


Lampiran 2 Uji coba dan tampilan media simulasi

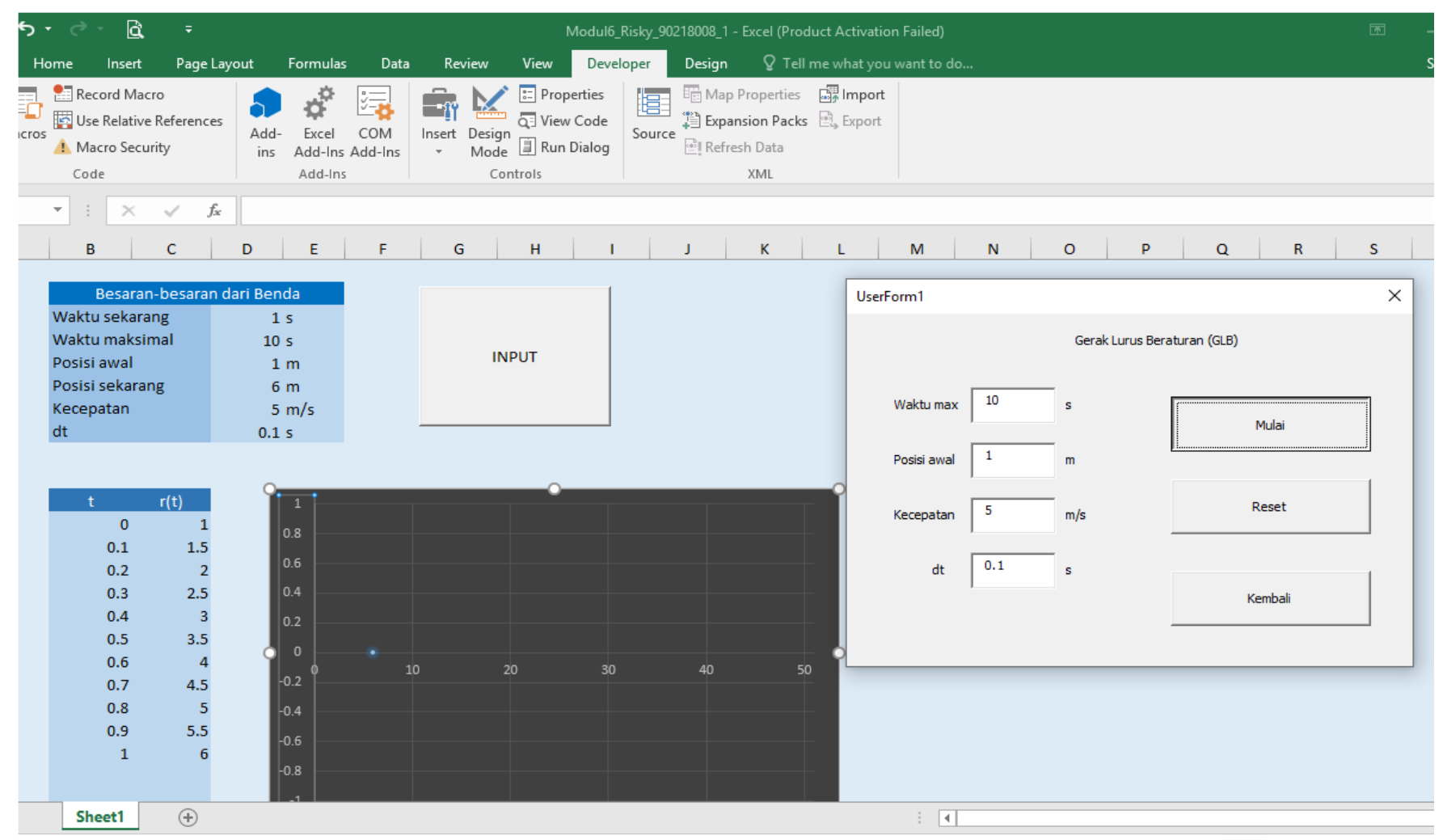

